\title{
PROPOSED CRITERIA TO DETERMINE TYPICAL VEHICULAR DRIVING CYCLES USING MINIMUM WEIGHTED DIFFERENCES
}

\author{
DANIEL CORDERO-MORENO*, DANILO DAVALOS, MATEO COELLO \& ROBERT ROCKWOOD \\ ERGON, Universidad Del Azuay, Cuenca, Ecuador
}

\begin{abstract}
Vehicular driving cycles are speed vs. time diagrams, which describe typical driving patterns within a given city or region. These diagrams are currently used to evaluate fuel consumption, exhaust emissions and to configure the powertrain of new vehicles, or vehicles already in use. For the latter application, it is necessary to determine a local driving cycle, which includes an altitude profile. There is no standard methodology for establishing a driving cycle. One of the currently used techniques is the analysis of a sample of trips, represented by specific parameters such as average speed, maximum acceleration, and idling time, among others, and then apply minimum weighted differences to obtain the typical driving cycle. This work proposes a methodology to select these parameters and their weights. This proposed methodology evaluates the energy demanded by the vehicle to overcome drag force $(\mathrm{Fd})$, rolling resistance (Rx), inertia (Ri) and resistance due to road gradient $(\mathrm{Rg})$. This study was performed in Cuenca, Ecuador, using a taxi to collect 512 trips in 30 days of tests. Finally a typical driving cycle, which includes an altitude profile was obtained.
\end{abstract}

Keywords: driving cycles, minimum weighted differences, driving parameters.

\section{INTRODUCTION}

Some parameters that need to be measured in vehicles prior to its commercial availability, include emission factors [g of pollutant $/ \mathrm{km}$ ] and fuel efficiency [km/L; MPG; or L/100 km]. These parameters are obtained on a chassis dynamometer (Fig. 1), where the driver follows a duty cycle, known as the driving cycle.

Currently, there are several standard driving cycles, among which FTP75 and NEDC (Fig. 2) stand out. These driving cycles are speed vs. time diagrams that represent what drivers typically do in a specific region or city. FTP 75 (Fig. 2(a)) was obtained in the United States in the 1970s [1], while NEDC (Fig. 2(b)) was applied since 2000 in Europe [2].

Although these cycles were obtained through real measurements, they are not necessarily representative cycles in different regions or cities, nor even in the locations where they were developed. Even so, they are the current standards and are used to certify vehicles around the world. This lack of real driving cycle representation has motivated the development of new measurements of driving cycles, such as the World-wide Harmonized Light Duty Test Cycle (WLTC) [4].

Vehicle certification of emissions and fuel economy is not the only use for driving cycles. They can be used, among other things, to configure the powertrain for a specific application [5], [6] and to predict the mass of pollutants that is emitted in a region or city [7], [8]. For these last applications, a representative local driving cycle is needed.

There are several methodologies to develop driving cycles [9]. A new methodology to define driving cycles in fixed routes is proposed based on previous studies on buses [10]. The bus driving cycle was obtained through real on-board measurements in a bus fleet.

${ }^{*}$ http://orcid.org/0000-0002-2155-2627 


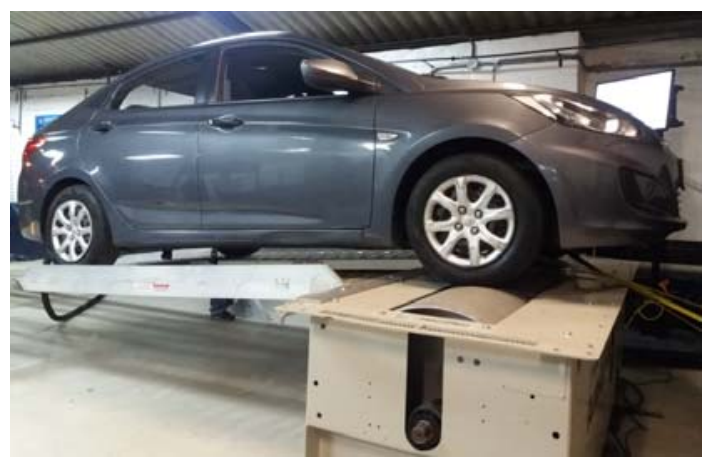

Figure 1: Driving cycle test on a chassis dynamometer.

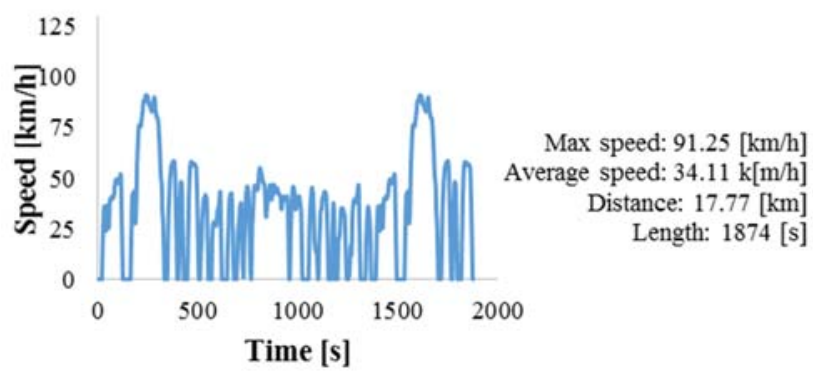

a) Federal Test Procedure 75 (FTP75)

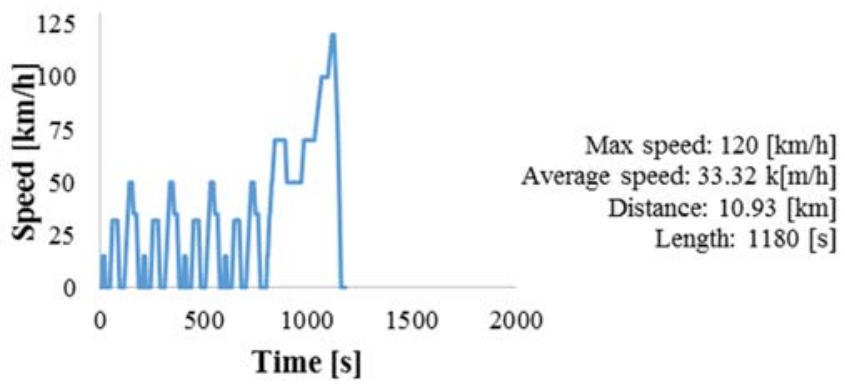

b) New European Driving Cycle (NEDC)

Figure 2: FTP75 and NEDC driving cycles with specific parameters [3].

Each measurement was represented by summary parameters, called characterization parameters (CP), to which minimum weighted differences (MWD) were applied. CP and their weights were suggested based on fuel consumption and tailpipe emissions [10]. The work presented here proposes a selection of $\mathrm{CP}$ and their weights based on energy demand. 


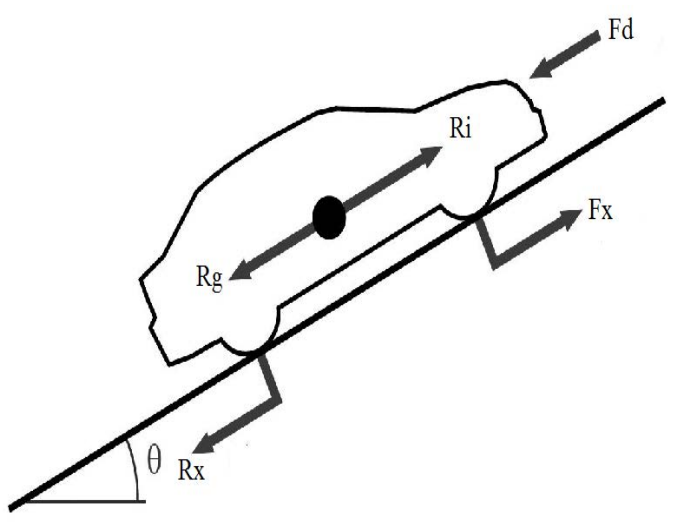

Figure 3: Free body diagram of a vehicle [12].

2 ENERGY DEMAND IN A VEHICLE

According to Gillespie [11], a vehicle needs to overcome four forces (Fig. 3) presented in eqn (1).

$$
F_{x}=F_{d}+R_{x}+R_{g}+R_{i}
$$

where:

$\mathrm{Fx}=$ Required wheel force $[\mathrm{N}]$

$\mathrm{Fd}=$ Drag force $[\mathrm{N}]$

$\mathrm{Rx}=$ Rolling resistance force $[\mathrm{N}]$

$\mathrm{Rg}=$ Force due to slope of the road $[\mathrm{N}]$

$\mathrm{Ri}=$ Force due to inertia $[\mathrm{N}]$

The components of each force are presented in eqn (2) through eqn (5).

$$
F_{d}=\frac{1}{2} C d * A * \rho * V^{2},
$$

where:

$\mathrm{Cd}=$ Drag coefficient $[-]$

$\mathrm{A}=$ Frontal area $\left[\mathrm{m}^{2}\right]$

$\rho=$ Air density $\left[\mathrm{kg} / \mathrm{m}^{3}\right]$

$\mathrm{V}=$ Vehicle speed $[\mathrm{m} / \mathrm{s}]$

$$
R_{x}=M * g * f r * \cos \theta,
$$

where:

$\mathrm{M}=$ Vehicle mass $[\mathrm{kg}]$

$\mathrm{g}=$ Gravity $\left[\mathrm{m} / \mathrm{s}^{2}\right]$

$\mathrm{fr}=$ Rolling resistance coefficient $[-]$

$\Theta=$ Road gradient $[\mathrm{rad}]$

$$
\begin{gathered}
R_{g}=M * g * \sin \theta, \\
R_{i}=M * a,
\end{gathered}
$$


where:

$\mathrm{a}=$ Acceleration $\left[\mathrm{m} / \mathrm{s}^{2}\right]$

Wheel power demand (Px) is calculated in Eqn.(6) and wheel energy demand $\left(\mathrm{Ex}^{+}\right)$is calculated in Eq. (7). It is important to mention that only positive energy is taken into account. Negative energy is wasted through the wheels because of the absence of an energy recovery system

$$
\begin{gathered}
P_{x}=F_{x} * V, \\
E_{x}+=\int P_{x} * d t
\end{gathered}
$$

With each force presented in eqn (1) is possible to calculate power and energy related to it. That means there is a power and energy demand due to drag, to rolling resistance, to road gradient and inertia. eqn (8) and eqn (9) present the formulas to calculate power and energy demand due to each force that a vehicle need to overcome.

$$
\begin{aligned}
P_{i} & =F_{i} * V, \\
E_{i}+= & =\int P_{i} * d t,
\end{aligned}
$$

where i stands for drag $(\mathrm{Fd})$, rolling resistance $(\mathrm{Rx})$, road slope $(\mathrm{Rg})$ and inertia $(\mathrm{Ri})$.

\section{DATA LOGGING}

The study presented here was performed in Cuenca-Ecuador. Cuenca is located in the south of Ecuador (Fig. 4) at $\sim 2500$ masl. Its area is approximately $72 \mathrm{~km}^{2}$. Mean temperature is about $15^{\circ} \mathrm{C}$.

Data was obtained with a GPS receiver in a taxi. GPS specifications are detailed in Table 1. In order to get data from the whole city, a taxi was selected. The taxi, shown in Fig. 5, was equipped with a GPS unit to provide the parameters shown in Table 1, and monitored for 30 days during normal usage. Trips in which the taxi was occupied with passengers and going from point $A$ to point $B$ within the city were considered valid trips.

In order to separate valid trips, defined as a passenger ride in the taxi, from the GPS data that was continuously collected, taximeter information was used.

Taximeter and GPS were synchronized so each valid trip was determined (Fig. 6). A total of 512 valid trips were monitored.

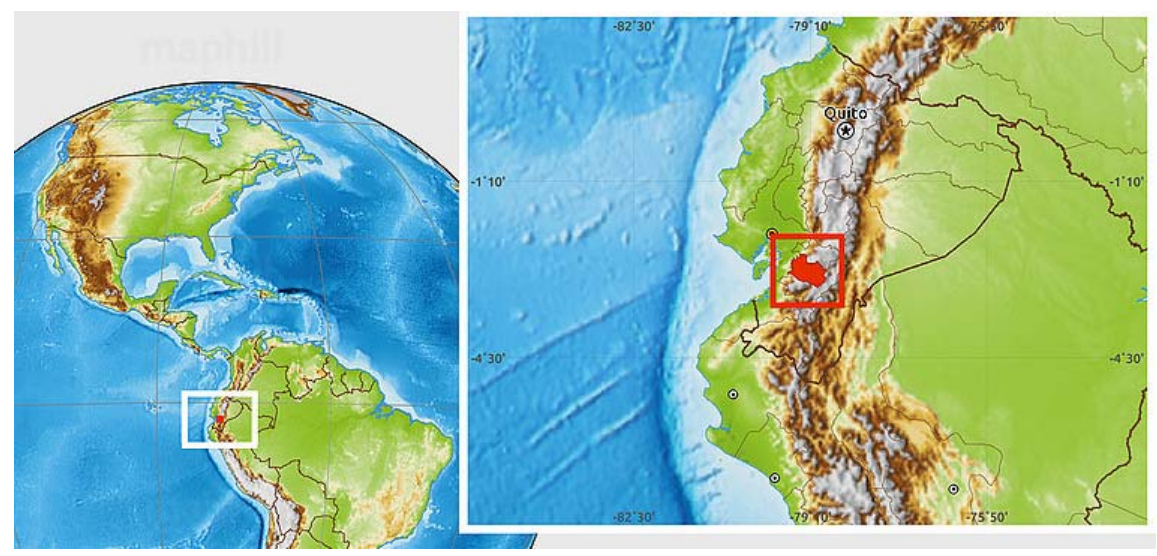

Figure 4: Cuenca location [13]. 
Table 1: GPS specifications [14].

\begin{tabular}{r|l}
\hline Parameter & \multicolumn{1}{c}{ Value } \\
\hline \hline Update rate & $1 /$ second, continuous \\
\hline PPS accuracy & \\
Position & $<10$ meters, typical \\
Velocity & .05 meter/sec steady state \\
\hline Position & $<5$ meters, typical \\
Velocity & .05 meter/sec steady state \\
\hline Electronic compass feature & \\
Accuracy & \pm 2 degrees with proper calibration \\
& $\begin{array}{l}\text { (typical); } \pm 5 \text { degrees extreme } \\
\text { northern } \\
\text { accuracy }\end{array}$ \\
& and southern latitudes \\
\hline Altimeter feature: & \\
Resolution & 1 foot \\
Range & $-2,000$ to 30,000 feet \\
\hline
\end{tabular}

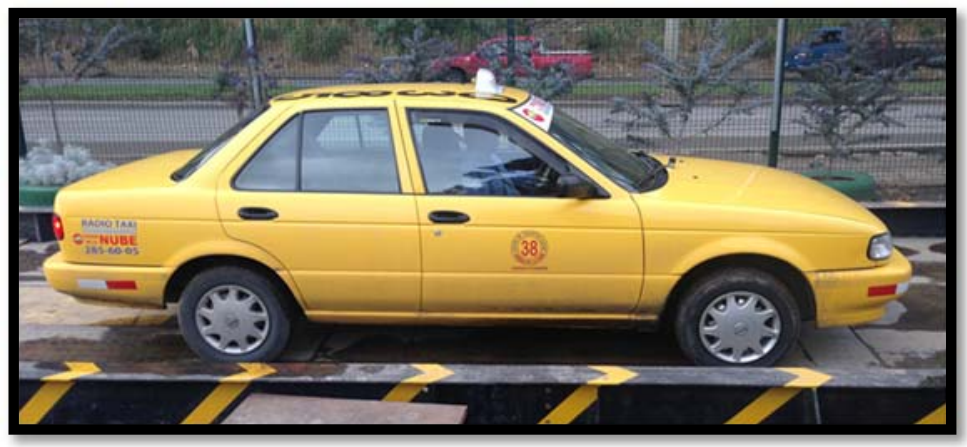

Figure 5: Taxi used for data logging.

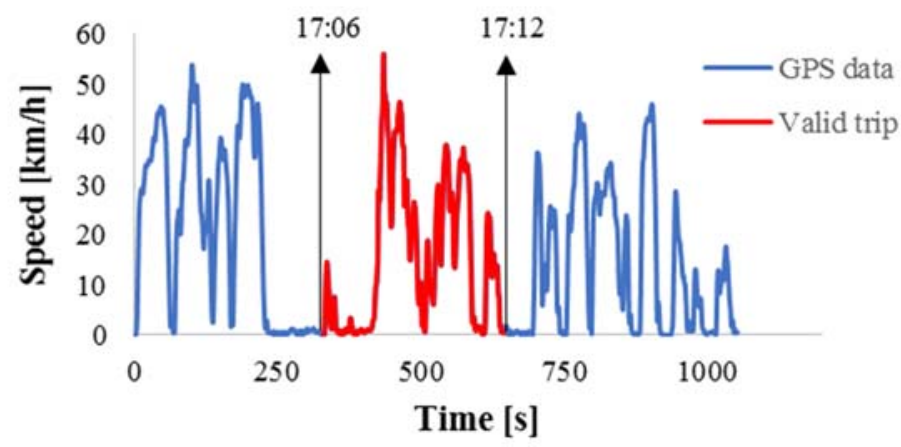

Figure 6: Valid trips from GPS data. 


\section{POWER AND ENERGY ANALYSIS}

Energy demand was calculated for each of the 512 valid trips. Table 2 presents vehicle information used to calculate values in eqn (1) through eqn (9).

With data in Table 2, and eqns (1-9), energy due to each type of load was calculated for each one of the trips. Table 3 shows the results of 512 trips where energy demand per trip was analysed with a 95-confidence interval.

Table 2: Vehicle and ambient parameters.

\begin{tabular}{|l|l|l|l|}
\hline Parameter & Symbol & Value & Unit \\
\hline Speed & V & From each trip & {$[\mathrm{m} / \mathrm{s}]$} \\
\hline Acceleration & $\mathrm{a}$ & From each trip & {$\left[\mathrm{m} / \mathrm{s}^{2}\right]$} \\
\hline Road slope & $\Theta$ & From each trip & {$[\mathrm{rad}]$} \\
\hline Mass & M & 1070 & {$[\mathrm{~kg}]$} \\
\hline Frontal area & A & 1.897 & {$\left[\mathrm{~m}^{2}\right]$} \\
\hline Drag Coefficient & Cd & 0.33 & {$[-]$} \\
\hline Rolling resistance coefficient & $\mathrm{fr}$ & 0.017 & {$[-]$} \\
\hline Air density & $\rho$ & 0.91 & {$\left[\mathrm{~kg} / \mathrm{m}^{3}\right]$} \\
\hline Gravity & $\mathrm{g}$ & 9.81 & {$\left[\mathrm{~m} / \mathrm{s}^{2}\right]$} \\
\hline
\end{tabular}

Table 3: Average energy demand per trip.

\begin{tabular}{|l|l|l|l|}
\hline Energy demand due to each load & Symbol & Value & Units \\
\hline Energy due to inertia & $\mathrm{E}_{\mathrm{Fd}}$ & $326.2 \pm 15.64$ & {$[\mathrm{Wh}]$} \\
\hline Energy due to rolling resistance & $\mathrm{E}_{\mathrm{Rx}}$ & $218.74 \pm 10.46$ & {$[\mathrm{Wh}]$} \\
\hline Energy due to road slope & $\mathrm{E}_{\mathrm{Rg}}$ & $175.68 \pm 12.52$ & {$[\mathrm{Wh}]$} \\
\hline Energy due to drag force & $\mathrm{E}_{\mathrm{Ri}}$ & $34.64 \pm 3.11$ & {$[\mathrm{Wh}]$} \\
\hline
\end{tabular}

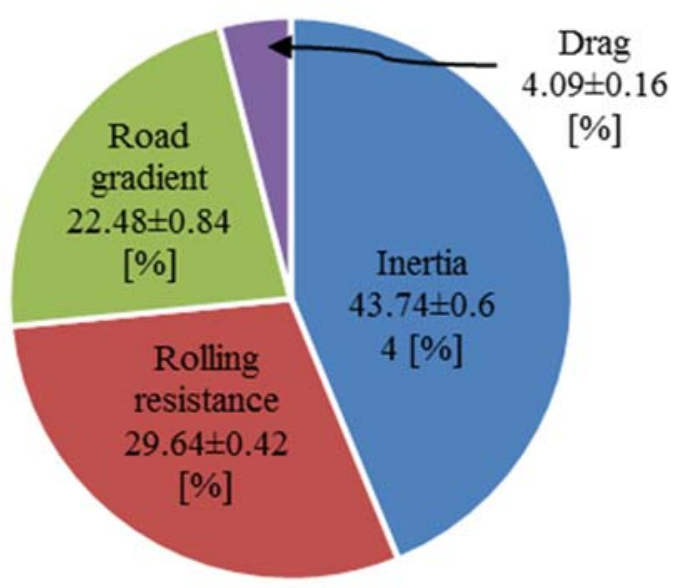

Figure 7: Contribution of each vehicle load in total energy demand (per trip). 


\section{DRIVING CYCLE SELECTION}

According to MWD-CP methodology [10], it is necessary to define characterization parameters and their weights. In this work the proposed characterization parameters are the energies demanded by types of loads, and their weights will be the percentage of their contribution to the total energy demand, which are presented in Fig. 7.

With data presented in Table 4, typical driving cycle that includes altitude profile, was selected.

Table 4: Characterization parameters and their corresponding weights.

\begin{tabular}{|l|c|}
\hline \multicolumn{1}{|c|}{ Characterization Parameters } & Weights \\
\hline Energy demanded due to inertia & 0.44 \\
\hline Energy demanded due to rolling resistance & 0.30 \\
\hline Energy demanded due to road gradient & 0.22 \\
\hline Energy demanded due to drag & 0.4 \\
\hline
\end{tabular}

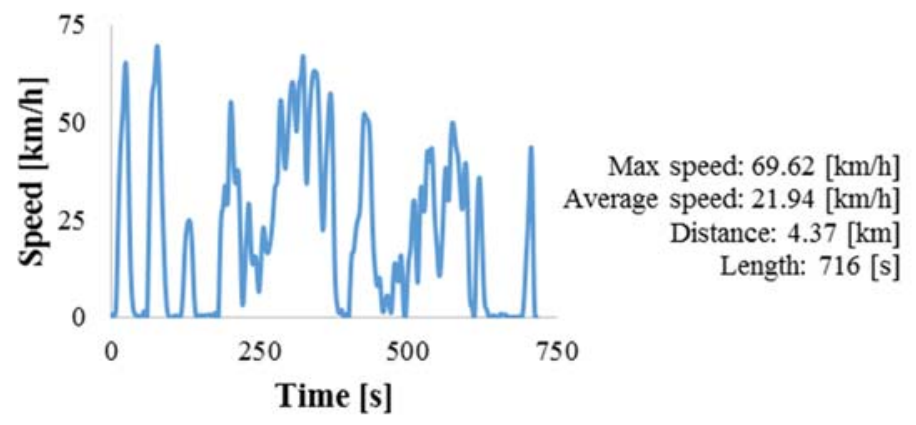

a) Typical driving cycle

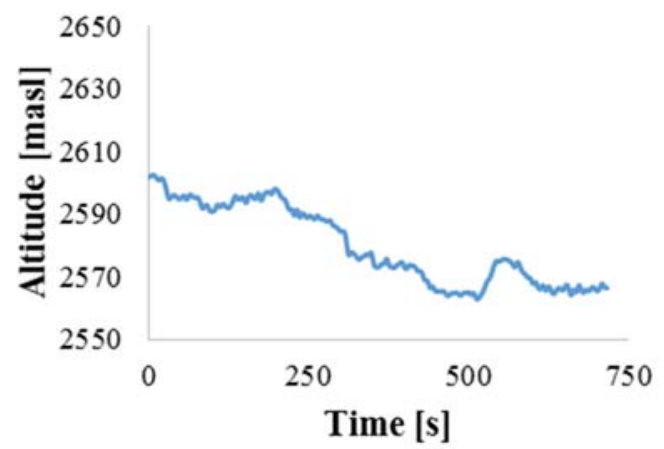

(b) A typical altitude profile for a selected cycle, Selected typical driving cycle and its altitude profile.

Figure 8: (a) Shows a typical driving cycle selected out of 512 valid trips; (b) Shows the altitude profile corresponding to selected typical driving cycles. 


\section{CONCLUSION}

Driving cycles are used mainly to evaluate existing vehicles on a chassis dynamometer. Nevertheless, typical driving cycles, including an altitude profile, allow better energy demand analysis through modelling and simulation.

Energy consumption analysis permits power train configuration and alternative power train evaluation to improve performance.

Following MWD-CP methodology, it is possible to select typical driving cycles out of real driving measurements in a city or region. It is important to set the boundaries for valid trips.

Specific parameters proposed in this work are the sum of energies due to every load in a car driving direction. Therefore, these parameters affect energy demand directly.

It is important to evaluate a larger number of vehicle samples in the future in order to validate a typical driving cycle for a city or region.

\section{ACKNOWLEDGEMENTS}

The authors wish to thank the contribution of engineer Washington Durán for lending us the taxi and Dr. Wayne Hanson for his collaboration reviewing this article.

\section{REFERENCES}

[1] Kruse, R.E. \& Huls, T.A., Development for the Federal Urban Driving Schedule. SAE Technical Paper 730553, 1973.

[2] Giakoumis, E.G., Driving and Engine Cycles, Springer International Publishing, 2016.

[3] Barlow, T.J., Latham, S., McCrae, I.S. \& Boulter, P.G., A Reference Book of Driving Cycles for use in the Measurement of Road Vehicle Emissions, Department of Transport PPR354, 2009.

[4] Tutuianu, M. et al., Development of the World-wide harmonized Light duty Test Cycle (WLTC) and a possible pathway for its introduction in the European legislation. Transportation Research Part D: Transport and Environment, 40, pp. 61-75, 2015.

[5] Dopson, D., Taitt, D. \& Sandford, M.H., Powertrain Systems Definition Process. SAE Technical Paper 950811, p. 15. 1995.

[6] Sandberg, T., Heavy Truck Modeling for Fuel Consumption Simulations and Measurements, Division of Vehicular Systems, Department of Electrical Engineering, Linköping University, 2001.

[7] Hung, W.T., Tong, H.Y., Lee, C.P., Ha, K. \& Pao, L.Y., Development of a practical driving cycle construction methodology: A case study in Hong Kong. Transportation Research Part D-Transport and Environment, 12, pp. 115-128, 2007.

[8] Sileghem, L., Bosteels, D., May, J., Favre, C. \& Verhelst, S., Analysis of vehicle emission measurements on the new WLTC, the NEDC and the CADC. Transportation Research Part D: Transport and Environment, 32, pp. 70-85, 2014.

[9] Xiao, Z., Dui-Jia, Z. \& Jun-Min, S., A Synthesis of Methodologies and Practices for Developing Driving Cycles. Energy Procedia, 16, Part C, pp. 1868-1873, 2012.

[10] Huertas, J.I., Díaz, J., Cordero, D. \& Cedillo, K., A new methodology to determine typical driving cycles for the design of vehicles power trains. International Journal on Interactive Design and Manufacturing (IJIDeM), pp. 1-8, 2017.

[11] Gillespie, T.D., Fundamentals of Vehicle Dynamics, Society of Automotive Engineers, 1992. 
[12] Galindo, E., Blanco, D., Brace, C., Chappell, E. \& Burke, R., Chassis Dynamometer Testing Addressing the Challenges of New Global Legislation (WLTP and RDE), Warrendale, Pennsylvania, USA: SAE International, 2017.

[13] Physical Location Map of Cuenca; Maphill Online, http:/www.maphill.com/ecuador/ azuay/cuenca/location-maps/physical-map/. Accessed on: 30 Jan. 2017.

[14] GPSMAP ${ }^{\circledR}$ 60Cx and 60CSx. GARMIN. Online, http://www8.garmin.com/specs/ GPSMAP60CSX0206.pdf. Accessed on: 28 Oct. 2016. 